\title{
Editorial: Life and Death: New Perspectives and Applications in Forensic Science
}

\author{
Gulnaz T. Javan ${ }^{1 *}$, M. Eric Benbow ${ }^{2,3,4,5}$ and T. Komang Ralebitso-Senior ${ }^{6}$ \\ ${ }^{1}$ Department of Physical Sciences and Forensic Science Programs, Alabama State University, Montgomery, AL, \\ United States, ${ }^{2}$ Department of Entomology, Michigan State University, East Lansing, MI, United States, ${ }^{3}$ Department of \\ Osteopathic Medical Specialties, Michigan State University, East Lansing, MI, United States, ${ }^{4}$ AgBioResearch, Michigan \\ State University, East Lansing, MI, United States, ${ }^{5}$ Ecology, Evolution and Behavior Program, Michigan State University, East \\ Lansing, MI, United States, ${ }^{6}$ School of Pharmacy and Biomolecular Sciences, Liverpool John Moores University, Liverpool, \\ United Kingdom
}

Keywords: microbial ecology, next-generation sequencing, vertebrate decomposition, necrobiome, thanatomicrobiome, forensic science

\section{Editorial on the Research Topic}

Life and Death: New Perspectives and Applications in Forensic Science

\section{INTRODUCTION}

Death is a universal phenomenon and what happens after life has led to extensive forensic ecology research. Consequently, we now know that the shell of the once living provides fertile ground for other life forms, spanning prokaryotic microbes to large, vertebrate scavengers. This ephemeral patch of newly available resources also provides rich sources of evidence that can be used in death investigation. In recent years there have been substantial advances in technology that have facilitated the research and application of human remains decomposition in ways that harness theory and basic understanding of the ecological and evolutionary sciences (Tomberlin et al., 2011). To that end, this special issue covers the most recent perspectives and research that explores the complex ways that the once living can provide important information to the forensic sciences, in ways that can ultimately be applied to the judicial system and its processes. It is within this context of linking basic research in death and decomposition to applications of forensics that the special topic was born.

Correspondence: Gulnaz T. Javan gjavan@alasu.edu

Specialty section:

This article was submitted to Evolutionary and Population Genetics,

a section of the journal

Frontiers in Ecology and Evolution

Received: 14 June 2021 Accepted: 09 August 2021 Published: 25 August 2021

Citation:

Javan GT, Benbow ME and Ralebitso-Senior TK (2021) Editorial: Life and Death: New Perspectives and Applications in Forensic Science.

Front. Ecol. Evol. 9:725046. doi: 10.3389/fevo.2021.725046

\section{THE RESEARCH TOPIC}

This Research Topic evaluates our understanding of the structure and function of necrobiome communities associated with the postmortem decomposition of vertebrate carrion. Mammalian hosts and their microbiomes undergo a process of ecological reciprocal adaptation. Changes in decomposition and postmortem perturbations may influence differentially dispersed populations of bacteria, fungi, and other microbes, resulting in dynamic changes or succession of postmortem microbial communities that also mediate how other scavengers (e.g., insects) detect and use the resource. Although there are several factors that affect this process, there is abundant evidence that understanding these communities can provide data of forensic importance. Some of that evidence lies within the papers that represent this special topic where the focus is both the basic understanding, and value, of using postmortem necrobiome and thanatomicrobiome communities in forensics. 
Forensic investigators are in need of modern tools to assist in constructing postmortem timelines, trace evidence relationships among subjects, and the circumstances of death or body relocation. The molecular tools used to evaluate the postmortem microbiome have potential to provide data for answering such questions of forensic importance including postmortem interval (PMI), i.e., the time elapsed since death or the postmortem submergence interval (PMSI). Current studies demonstrate the feasibility of using postmortem metrics of invertebrates, vertebrates, microbes, and their molecules as forensic tools, ranging from PMI estimates to trace evidence biomarkers. This Research Topic has brought fresh and innovative science for solving death investigations, using cutting-edge technologies concerning the community of organisms that detect and use carcasses in ways that can be studied to inform forensic investigations. We use the collection to highlight how the microbial, soil, scavengers, and mRNA transcript census in and/or around the vertebrate body changes postmortem as a function of time and temperature.

\section{PERSPECTIVES OF STATE OF THE ART AND ITS FUTURE}

It is important to reflect on the scientific journey of using microand macroorganisms in forensic science, the technology and methods that are driving this discipline, and the future potential while fully cognizant of the limitations. Such perspectives are provided by Jordan and Mills on the history of different DNA typing methods as applied to human and non-human DNA, and Roy et al. with a comprehensive review on thanatogenomics as a tool of enormous potential in forensic medicine.

\section{POSTMORTEM HUMAN MICROBIOME}

Saliva is an essential body fluid and trace evidence, while the human buccal cavity is an established go-to area of sampling for human DNA in crime scenes as a means of identifying the victim of crime (e.g., bites, sexual assault, missing persons) or the suspected offender. It is sensible, therefore, to profile the microbiome of the oral cavity to determine time since deposition (López et al. re saliva and multiplex qPCR assay) and postmortem interval relative to the decomposition timeline (Ashe et al. who used a suite of culture-based, metagenomics and metatranscriptomic methods). Similarly, Ahannach et al. provided a comprehensive review highlighting the value, and hurdles that must be addressed, of microbial forensic analyses of skin, mouth and vaginal samples to complement and strengthen forensic investigations, particularly for sexual assault and femicide cases.

The manner and cause of death is central to autopsy within human pathology. Forensic pathology is an established science for the resolution of crimes, particularly in instances of unexplained deaths. Kaszubinski et al. studied postmortem microbiomes following deaths from a range of causes and identified the potential role of microbial community dynamics to help determine manner and cause of death (M/COD), including relative to antemortem health status.
Applying cutting-edge technologies for knowledge development in new contexts typically leads to further seminal research questions. For example: Are there organs that are better or more accurate sources of the thanatomicrobiome for enhanced PMI calculations?; Is there a point or interval since death at which organ-based microbiome can no longer be used reliably for accurate PMI determination? Thus Lutz et al. studied the thanatomicrobiome of six human reproductive and non-reproductive organs during extended postmortem interval, and identified several significant relationships between PMI, organ group type and relative abundances of the four most abundant bacterial orders (Burkholderiales, Clostridiales, MLE1-12, Saprospirales).

\section{THE ROLE OF ANIMAL MODELS}

Although certain questions cannot be answered fully with using mammalian surrogates, many global regions and countries do not yet have the ethical framework required to conduct forensic decomposition, postmortem research and field experiments using human remains. As a result, requisite and essential research is being implemented with the use of different animals, mostly pigs (Sus scrofa), laboratory mice (Mus musculus Linnaeus), and rats (Rattus norvegicus Berkenhout), as surrogates for the human cadaver. While the benefits of mammalian proxies are well-recognized, the transferability of animal-derived data to human postmortem ecology e.g., postmortem interval, postburial interval (PBI), and PMSI determinations is justifiably under the microscope (Matuszewski et al., 2019). This, therefore, necessitates special scrutiny as shown by DeBruyn et al. who compared the decomposition of human cadavers and pigs as mammalian surrogates.

Research and knowledge development cannot stop until the required ethical approvals and guidelines are in place. As a result, Gates et al. presented their work within a medicolegal context using pigs to understand the role and/or occurrence of postmortem bacterial translocation in sudden unexplained death in infants (SUDI).

Carter et al. (2007) defined the concept of a cadaver decomposition island (CDI) and highlighted the need to understand this unique ecosystem as part of extending the forensic toolkit. To this end, Bisker et al., in the first of such studies, applied a combination of Hill ecological indices (Chao et al., 2010, 2014), metagenomics, physicochemical and edaphic factor analyses to determine PMI during a 24-month subsurface decomposition of Sus scrofa domesticus. In a similar context, Procopio et al. evidenced the importance of fungal metabarcoding and showed that mycoforensics needs to be given similar attention and utility as bacteria-based microbial ecology forensics.

\section{METHOD DEVELOPMENT AND CROSS-DISCIPLINARY WORK}

Successful resolution of unexplained death, or that resulting from criminal activity, is a process that inherently crosses (forensic) disciplines and scientific practices. This Research Topic has 
highlighted how contemporary techniques have substantially advanced the forensic field. For example, forensic entomology is one of the earliest and most established disciplines where minimum time since death $\left({ }_{\min } \mathrm{PMI}\right)$ has been used globally for the resolution of crimes (Tomberlin and Benbow, 2015; Byrd and Tomberlin, 2019), where early approaches typically measured the developmental rates and successional patterns of insects (e.g., Archer and Elgar, 2003). Presently, Pimsler et al. applied qPCRbased transcriptomics to understand the decompositional role of Chrysomya rufifacies at a molecular level, thus demonstrating the core theme in our Research Topic; that of the role of adopting cutting-edge techniques to advance translational forensic science.

\section{AUTHOR CONTRIBUTIONS}

GJ, ME, and TR-S contributed to the writing and editing of this manuscript.

\section{REFERENCES}

Archer, M. S., and Elgar, M. A. (2003). Yearly activity patterns in southern Victoria (Australia) of seasonally active carrion insects. Forensic Sci. Int. 132, 173-176. doi: 10.1016/S0379-0738(03)00034-3

Byrd, J. H., and Tomberlin, J. K. (2019). Forensic Entomology: The Utility of Arthropods in Legal Investigations. Boca Raton, FL: CRC Press.

Carter, D. O., Yellowlees, D., and Tibbett, M. (2007). Cadaver decomposition in terrestrial ecosystems. Naturwissenschaften 94, 12-24. doi: 10.1007/s00114-006-0159-1

Chao, A., Chiu, C. -H., and Jost, L. (2010). Phylogenetic diversity measures based on Hill numbers. Philos. Trans. R. Soc. B Biol. Sci. 365, 3599-3609. doi: $10.1098 /$ rstb. 2010.0272

Chao, A., Chiu, C. -H., and Jost, L. (2014). Unifying species diversity, phylogenetic diversity, functional diversity, and related similarity and differentiation measures through Hill numbers. Annu. Rev. 45, 297-324. doi: 10.1146/annurev-ecolsys-120213-091540

Matuszewski, S., Hall, M. J. R., Moreau, G., Schoenly, K. G., Tarone, A. M., and Villet, M. H. (2019). Pigs vs people: the use of pigs as analogues for humans in forensic entomology and taphonomy research. Int. J. Legal Med. 134, 798-810. doi: 10.1007/s00414-019-02074-5

Tomberlin, J. K., and Benbow, M. E. (2015). Forensic Entomology: International Dimensions and Frontiers. Boca Raton, FL: CRC Press.

Tomberlin, J. K., Benbow, M. E., Tarone, A. M., and Mohr, R. M. (2011). Basic research in evolution and ecology enhances

\section{FUNDING}

While this Editorial was written, GJ was funded by the National Science Foundation (NSF) grant HRD 2011764 and the National Institute of Justice (NIJ) 2017-MU-MU-4042. MB was supported by a grant from the National Institute of Justice, Office of Justice Programs, U.S. Department of Justice awarded (202075-CX-0012). TR-S was supported by the QR-Global Challenges Research Fund (2019/2020) of Liverpool John Moores University.

\section{ACKNOWLEDGMENTS}

We are grateful to the 25 authors from around the world who contributed to this Research Topic and provided expert coverage of new perspectives and applications in forensic science through 12 original research and review articles. Also, we warmly thank all the dedicated reviewers for their contributions to this eBook and the editorial support of the Journal.

$\begin{aligned} & \text { forensics. Trends Ecol. Evol. 26, 53-55. doi: 10.1016/j.tree.2010. } \\ & 12.001\end{aligned}$

Author Disclaimer: Points of view in this document are those of the authors and do not necessarily represent the official position or policies of the U.S. Department of Justice.

Conflict of Interest: The authors declare that the research was conducted in the absence of any commercial or financial relationships that could be construed as a potential conflict of interest.

Publisher's Note: All claims expressed in this article are solely those of the authors and do not necessarily represent those of their affiliated organizations, or those of the publisher, the editors and the reviewers. Any product that may be evaluated in this article, or claim that may be made by its manufacturer, is not guaranteed or endorsed by the publisher.

Copyright (C) 2021 Javan, Benbow and Ralebitso-Senior. This is an open-access article distributed under the terms of the Creative Commons Attribution License (CC BY). The use, distribution or reproduction in other forums is permitted, provided the original author(s) and the copyright owner(s) are credited and that the original publication in this journal is cited, in accordance with accepted academic practice. No use, distribution or reproduction is permitted which does not comply with these terms. 